\title{
Regression of esophageal varices and splenomegaly in two patients with hepatitis-C-related liver cirrhosis after interferon and ribavirin combination therapy
}

\author{
Soon Jae Lee', Yoo-Kyung Cho', Soo-Young Na', Eun Kwang Choi', Sun Jin Boo', Seung Uk Jeong', Hyung Joo Song', \\ Heung Up Kim', Bong Soo Kim², Byung-Cheol Song ${ }^{1}$ \\ Department of Internal Medicine ${ }^{1}$ and Radiology², Jeju National University School of Medicine, Jeju, Korea
}

Some recent studies have found regression of liver cirrhosis after antiviral therapy in patients with hepatitis C virus (HCV)related liver cirrhosis, but there have been no reports of complete regression of esophageal varices after interferon/ peg-interferon and ribavirin combination therapy. We describe two cases of complete regression of esophageal varices and splenomegaly after interferon-alpha and ribavirin combination therapy in patients with HCV-related liver cirrhosis. Esophageal varices and splenomegaly regressed after 3 and 8 years of sustained virologic responses in cases 1 and 2 , respectively. To our knowledge, this is the first study demonstrating that complications of liver cirrhosis, such as esophageal varices and splenomegaly, can regress after antiviral therapy in patients with HCV-related liver cirrhosis.

(Clin Mol Hepatol 2016;22:390-395)

Keywords: Esophageal varices; Splenomegaly; Regression; Hepatitis C, Liver cirrhosis; Interferon; Ribavirin

\section{INTRODUCTION}

The benefit of sustained virologic response (SVR) after interferon-based antiviral therapy, defined as HCV RNA negative for 24 weeks after cessation of treatment, in patients with chronic hepatitis C (CHC) is well-documented. ${ }^{2,3}$ Recent studies also suggest that liver cirrhosis is reversible after antiviral therapy in patients with $\mathrm{CHC}^{4-6}$ However, there is little data about the regression of cirrhosis-related complication, such as esophageal varices and splenomegaly, in patients with HCV-related liver cirrhosis who are treated with interferon-alpha and ribavirin combination therapy. We observed two patients with HCV liver cirrhosis, who achieved SVR after treatment with interferon-alpha and ribavirin combina- tion, go into complete remission of esophageal varices and splenomegaly.

To our knowledge, this is the first report to demonstrate that cirrhosis-related complications, such as esophageal varices and splenomegaly, can regress after antiviral therapy in patients with HCV-related liver cirrhosis.

\section{CASE REPORT}

\section{Case 1}

A 57-year-old woman visited our outpatient clinic with positive

\section{Abbreviations:}

ALT, alanine aminotransferase; AST, aspartate aminotransferase; CHC, chronic hepatitis $\mathrm{C}$; HCV, hepatitis $\mathrm{C}$ virus; SVR, sustained virologic response
Corresponding author : Byung-Cheol Song

Department of Internal Medicine, Jeju National University School of Medicine, 15 Aran 13-gil, Jeju 63241, Korea

Tel: +82-64-754-8177, Fax: +82-64-717-1131

E-mail: drsong@jejunu.ac.kr 

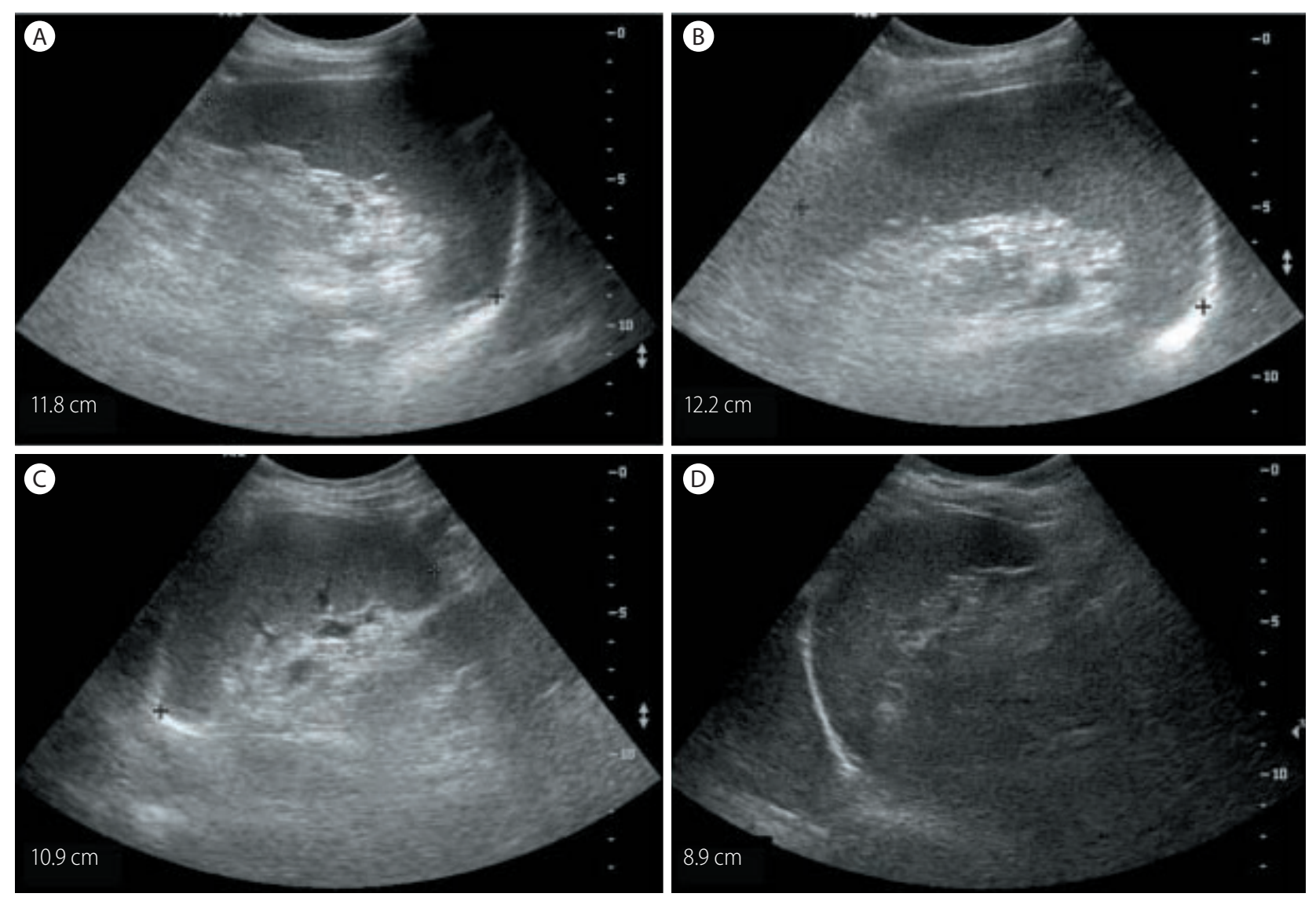

Figure 1. Abdominal ultrasonographic findings in case 1. Initial abdominal ultrasonography revealed chronic liver disease with mild splenomegaly $(11.8 \mathrm{~cm})($ A). The splenomegaly had progressed to $12.2 \mathrm{~cm}$ after 1 years of a sustained virologic response (SVR) (B). The spleen size subsequently decreased to $10.9 \mathrm{~cm}$ after 2 years of an SVR (C) and to $8.9 \mathrm{~cm}$ after 3 years of an SVR (D).

anti-HCV test results on routine medical check-up. Initial laboratory data were as follows: white blood cell count of $3,800 / \mu \mathrm{L}$ ( N:4,000-10,000), hemoglobin of $11.8 \mathrm{~g} / \mathrm{dL}(\mathrm{N}: 13-17)$, platelet count of 72,000/ $\mathrm{LL}(\mathrm{N}: 150,000-450,000)$, creatinine of $0.7 \mathrm{mg} / \mathrm{dL}$ (0.9-1.3), aspartate aminotransferase (AST) level of 21 IU/L (N:838), alanine aminotransferase (ALT) level of $15 \mathrm{IU} / \mathrm{L}$ (N:4-44), total bilirubin of $0.4 \mathrm{mg} / \mathrm{dL}$ (N:0.2-1.2), albumin of $4.3 \mathrm{~g} / \mathrm{dL}$ ( $\mathrm{N}: 3.8-5.3)$, and prothrombin time of 1.06 international normalization ratio (INR) (N:0.88-1.2). The HBsAg and anti-HBs were negative, but anti-HCV was positive. The level of HCV RNA was $1.32 \times 10^{5}$ copies/mL and HCV genotype was 2a.

Abdominal ultrasonography showed coarse echogenicity of the liver parenchyma and splenomegaly (long axis of spleen, $11.8 \mathrm{~cm}$ ). (Fig. 1A) Esophagogastroduodenoscopy showed presence of minimal to $F 1$ esophageal varices on the lower esophagus and portal hypertensive gastropathy (Fig. 2A). Based on these results, the patient was diagnosed with HCV-related liver cirrhosis. Interferon-alpha $2 \mathrm{~b}$ and ribavirin combination therapy commenced from June
30, 2004 for 24 weeks. The patient achieved SVR. HCV RNA was negative, and normal ALT persisted during follow-up. After 1 year of SVR, esophageal varices progressed to F1-F2 (Fig. 2B). After 2 years of SVR, esophageal varices decreased to minimal varices, and regressed completely (Fig. 2C, 2D) after 3 years of SVR. Abdominal computed tomography taken after 9 years of SVR showed no evidence of esophageal, para-esophageal varices, or portosytemic shunt (Fig. 3). The spleen size increased to $12.2 \mathrm{~cm}$ after 1 years of SVR (Fig 1B), however, its size decreased to $10.9 \mathrm{~cm}$ after 2 year of SVR (Fig. 1C), and decreased further to $8.9 \mathrm{~cm}$ (Fig. 1D) after 3 years of SVR. WBC and platelet counts increased to 5,200/ $\mu \mathrm{L}$ and $171,000 / \mu \mathrm{L}$ at last follow up, respectively. Last examination was performed on August 14, 2014. There was no evidence of esophageal varices, splenomegaly or thrombocytopenia.

\section{Case 2}

A 60-year-old man diagnosed with CHC was referred to the 


\section{CMHH}

Clin Mol Hepatol

Volume 22 Number 3 September 2016

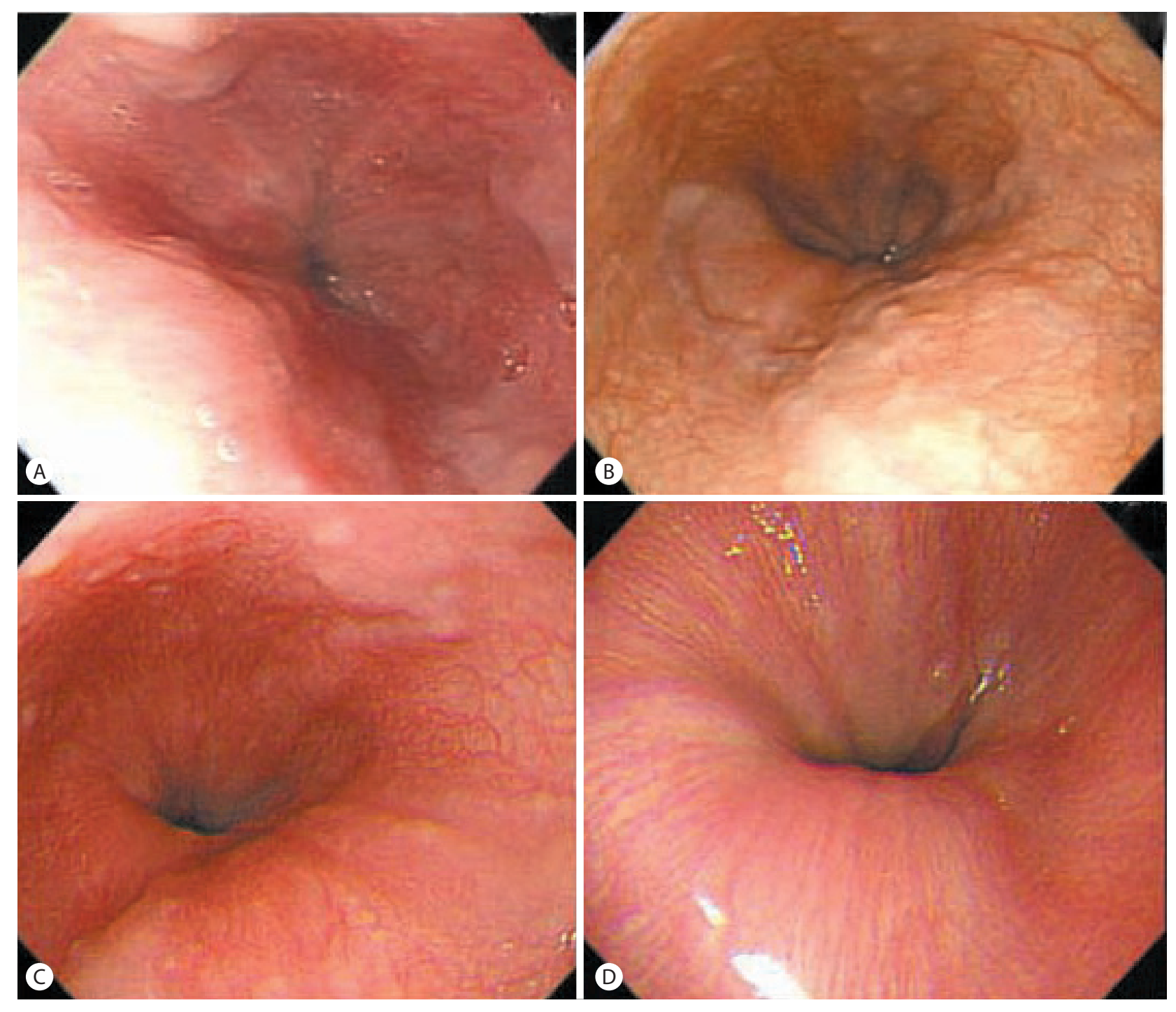

Figure 2. Esophagogastroduodenoscopic findings in case 1. Minimal to F1 esophageal varices in the lower esophagus were observed prior to applying antiviral therapy (A). Esophageal varices had progressed to F1/F2 after 1 year of an SVR (B), and then decreased to minimal or F1 after 2 years of an SVR (C) and regressed completely after 3 years of an SVR (D).

outpatient clinic for antiviral therapy in January 13, 2004. Initial laboratory data were as follows: WBC of $6,200 / \mu \mathrm{L}$, hemoglobin of $16.0 \mathrm{~g} / \mathrm{dL}$, platelet count of $106,300 / \mu \mathrm{L}$, creatinine of $0.9 \mathrm{mg} / \mathrm{dL}$, AST level of $182 \mathrm{IU} / \mathrm{L}$, ALT level of $238 \mathrm{lU} / \mathrm{mL}$, total bilirubin level of $1.1 \mathrm{mg} / \mathrm{dL}$, albumin level of $4.2 \mathrm{~g} / \mathrm{dL}$, and prothrombin time of 1.07 INR. The HBsAg and anti-HBs were negative, but anti-HCV was positive. The level of HCV RNA was $2.26 \times 10^{5}$ copies $/ \mathrm{ml}$ and HCV genotype was 2a.

Esophagogastroduodenoscopy revealed presence of F1 esophageal varices on the lower esophagus and portal hypertensive gastropathy (Fig. 4A). Abdominal ultrasonography showed coarse echogenicity of the liver parenchyma and mild splenomegaly (long axis of spleen, $10.2 \mathrm{~cm}) .^{7}$ He was treated with interferon alpha and ribavirin combination for 24 weeks and achieved SVR. During follow up, esophageal varices decreased in size (Fig. 4B) and completely regressed after 8 years of SVR (Fig. 4C). The spleen size decreased to $8.9 \mathrm{~cm}$ and platelet counts increased to $256,000 / \mu \mathrm{L}$ after 8 years of SVR.

\section{DISCUSSION}

Esophageal varices are one of the major complications in patients with liver cirrhosis. Prevalence of esophageal varices is $40 \%$ 

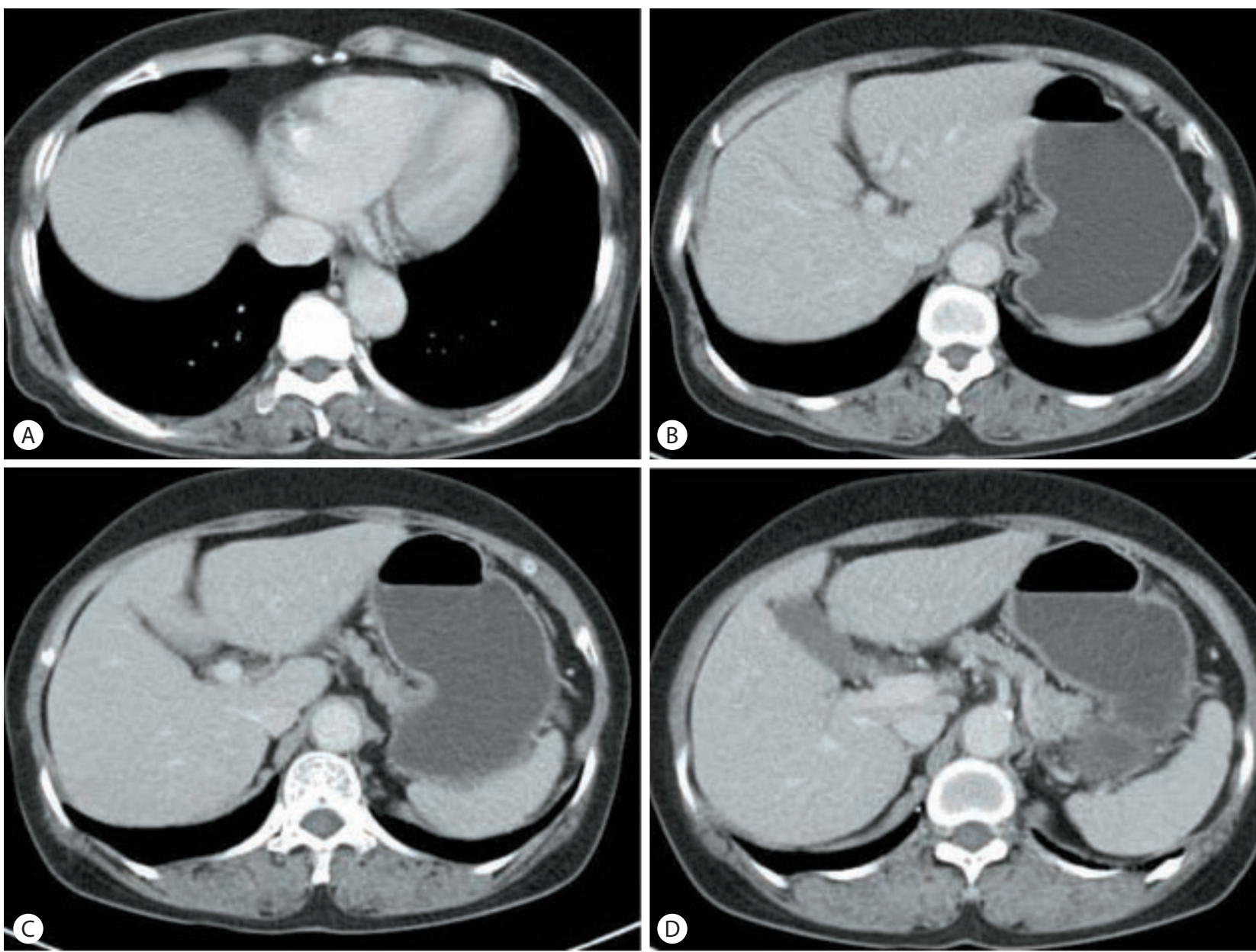

Figure 3. (A-D) Computed tomographic findings in case 1. There was no evidence of esophageal, para-esophageal varices, or portosystemic shunt in abdominal computed tomography performed after 9 years of an SVR.

in patients with Child-Pugh class A, and up to $80 \%$ in Child-Pugh class $C$. It is well known that variceal bleeding is a fatal complication in patients with liver cirrhosis. ${ }^{8}$

Histological changes in liver cirrhosis have been believed to be irreversible for a long time. ${ }^{9}$ However, recent studies showed variable degrees of regression of liver cirrhosis in patients who achieved SVR after antiviral therapy. ${ }^{4-6}$ Recent meta-analysis also showed that 73 of 137 patients (53\%) who achieved SVR had regression of liver cirrhosis. ${ }^{4}$ In addition, Bruno et al. demonstrated that the achievement of SVR prevents the development of esophageal varices in patients with compensated HCV-related liver cirrhosis. ${ }^{10}$ Therefore, it is now clear that the liver cirrhosis is not a static event but a dynamic and regulated process that is reversible if the underlying cause of liver injury is eliminated. ${ }^{11}$

Nevertheless, little data are available if complications of cirrhosis, such as esophageal varices and splenomegaly, can regress after antiviral therapy. Some studies reported spontaneous regres- sion of esophageal varices in patient with HBsAg loss or abstinence from alcohol drinking, ${ }^{12,13}$ and Koga et al. reported 3 cases whose esophageal varices regressed after lamivudine therapy. ${ }^{14}$ However, there was no report to demonstrate regression of esophageal varices and splenomegaly after antiviral therapy in patients with HCV-related liver cirrhosis.

Previous studies suggest that regression of liver cirrhosis usually occurred after 3 years of anti-viral therapy. ${ }^{4}$ In our study, regression of esophageal varices occurred after 3 years and 8 years of SVR in each patient. This phenomenon might be attributable to lowering portal venous pressure following improvement of fibrosis or cirrhosis after SVR.

To our knowledge, this is the first report demonstrating that complication of liver cirrhosis, such as esophageal varices and splenomegaly, can be reversed after sustained eradication of HCV replication. 

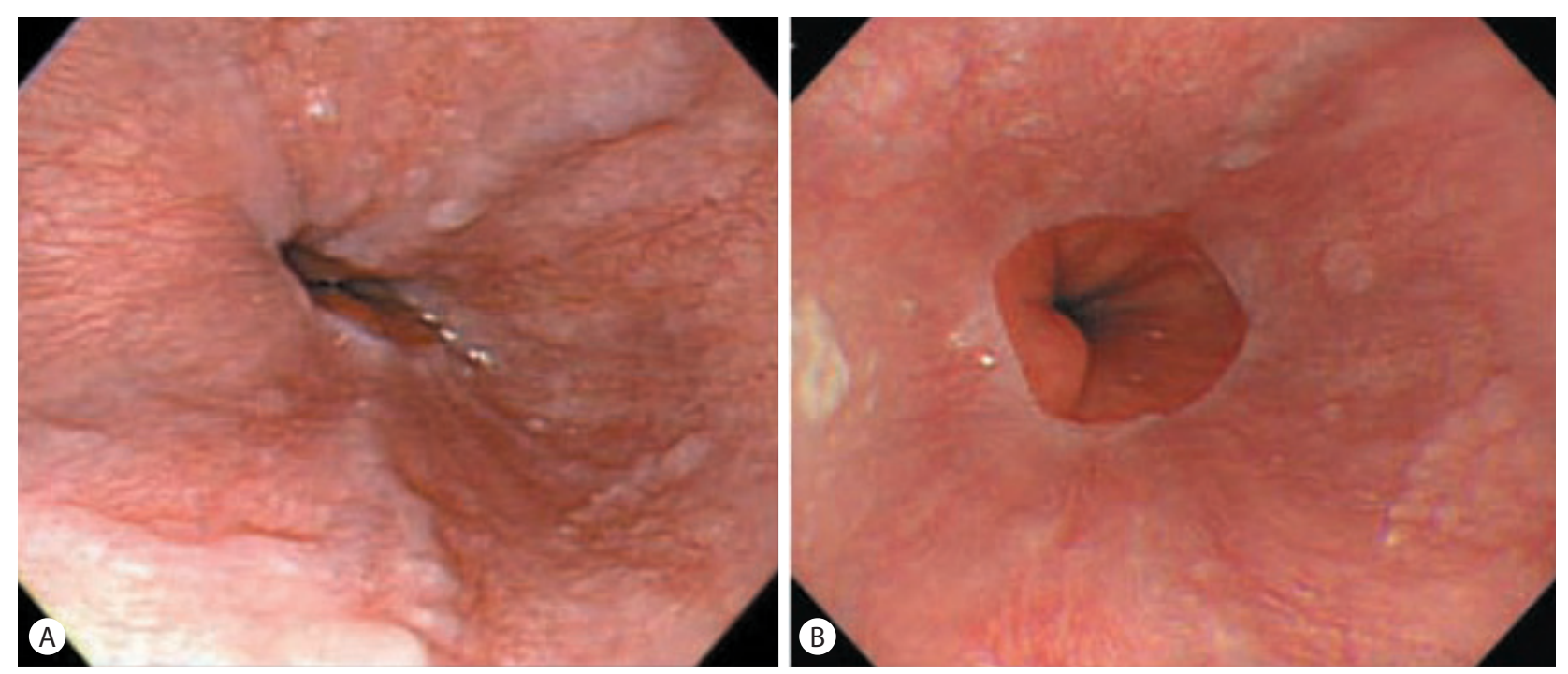

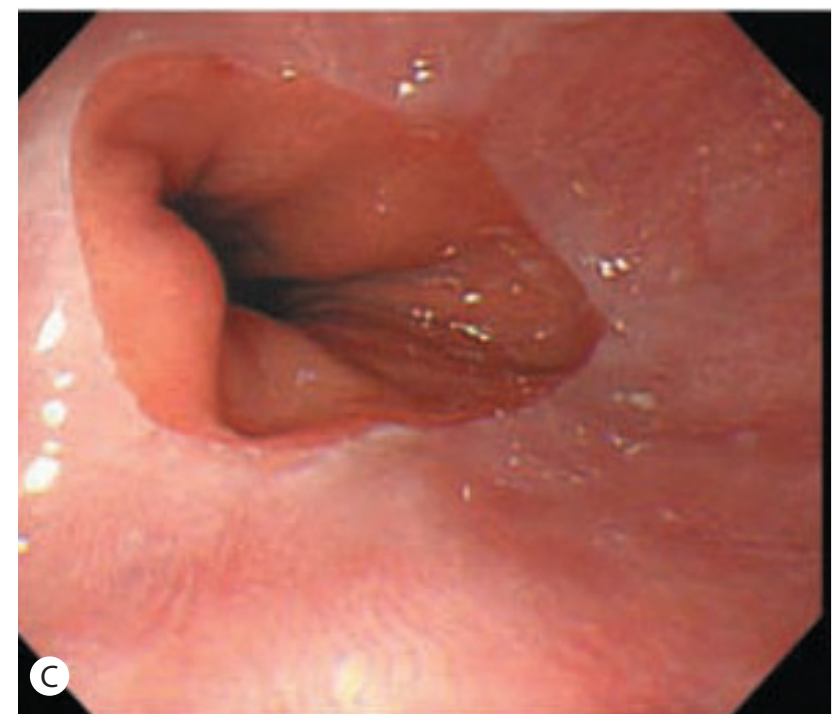

\section{Conflicts of Interest}

The authors have no conflicts to disclose.

\section{REFERENCES}

1. Ghany MG, Strader DB, Thomas DL, Seeff LB. Diagnosis, management, and treatment of hepatitis $C$ : an update. Hepatology 2009;49:1335-1374.

2. George SL, Bacon BR, Brunt EM, Mihindukulasuriya KL, Hoffmann J, Di Bisceglie AM. Clinical, virologic, histologic, and biochemical outcomes after successful HCV therapy: a 5-year follow-up of 150 patients. Hepatology 2009;49:729-738.

3. Shiratori Y, Imazeki F, Moriyama M, Yano M, Arakawa Y, Yokosuka O, et al. Histologic improvement of fibrosis in patients with hepatitis $C$ who have sustained response to interferon therapy. Ann Intern Med
Figure 4. Esophagogastroduodenoscopic findings in case 2. F1 esophageal varices were evident in the lower esophagus (A). Esophageal varices decreased to minimal after 6 years of an SVR (B) and had regressed completely after 8 years of an SVR (C).

\section{0;132:517-524.}

4. Akhtar E, Manne V, Saab S. Cirrhosis regression in hepatitis C patients with sustained virological response after antiviral therapy: a meta-analysis. Liver Int 2015;35:30-36.

5. Veldt BJ, Heathcote EJ, Wedemeyer H, Reichen J, Hofmann WP, Zeuzem $\mathrm{S}$, et al. Sustained virologic response and clinical outcomes in patients with chronic hepatitis $C$ and advanced fibrosis. Ann Intern Med 2007;147:677-684.

6. Mallet V, Gilgenkrantz $H$, Serpaggi J, Verkarre V, Vallet-Pichard A, Fontaine $H$, et al. Brief communication: the relationship of regression of cirrhosis to outcome in chronic hepatitis C. Ann Intern Med 2008;149:399-403.

7. Brown JJ, Naylor MJ, Yagan N. Imaging of hepatic cirrhosis. Radiology 1997;202:1-16.

8. Garcia-Tsao G1, Sanyal AJ, Grace ND, Carey W. Prevention and management of gastroesophageal varices and variceal hemorrhage in 
cirrhosis. Hepatology 2007;46:922-938.

9. Friedman SL, Bansal MB. Reversal of hepatic fibrosis -- fact or fantasy? Hepatology 2006; 43(2 Suppl 1):S82-S88.

10. Bruno S, Crosignani A, Facciotto C, Rossi S, Roffi L, Redaelli A, et al. Sustained virologic response prevents the development of esophageal varices in compensated, Child-Pugh class A hepatitis $C$ virusinduced cirrhosis. A 12-year prospective follow-up study. Hepatology 2010;51:2069-2076.

11. Bonis PA, Friedman SL, Kaplan MM. Is liver fibrosis reversible? N Engl J Med 2001;344:452-454.

12. Muting D, Kalk JF, Fischer R, Wiewel D. Spontaneous regression of oesophageal varices after long-term conservative treatment. Retrospective study in 20 patients with alcoholic liver cirrhosis, posthepatitic cirrhosis and haemochromatosis with cirrhosis. J Hepatol 1990;10:158-162.

13. Calès $P$, Burtin $P$, Oberti F. Spontaneous regression of esophageal varices is a phenomenon that has spontaneously disappeared from our memory. J Hepatol 1991;12:263-264.

14. Koga H, Ide T, Oho K, Kuwahara R, Hino T, Ogata K, et al. Lamivudine treatment-related morphological changes of esophageal varices in patients with liver cirrhosis. Hepatol Res 2007;37:503-509. 